\title{
Negotiated Interaction in Teacher-Led versus Peer Group Adult ESL Discussions
}

Ling Shi

This study investigated how teachers and learners negotiated meaning in three teacher-led whole-class and nine peer group prewriting discussions in a pre-university ESL program. By analyzing various interaction features such as comprehension and confirmation checks, clarification and feedback requests, self-and other-corrections, and self-and other-completion, the study found that although peer discussions had high frequencies of negotiation, these negotiations were restricted compared with the extended negotiations in teacher-led discussions. Also, peer groups, where students showed more initiation to modify syntax, lexis, and meaning were limited compared with the targetlike forms in teacher-led error corrections. Students' feedback suggested that they perceived peer and teacher talk to complement each other to meet various needs of the learners as useful language learning experiences.

Educational research on negotiation attempts to explore a collaborative effort in conversational interaction that is believed to cultivate language learning. In other words, researchers have tried to verify the relationship between language learning and the signals of incomprehension that trigger learner adjustments in their interlanguage. The interaction features, referred to as "repair features" (Long \& Porter, 1985), "verbal feedback" (Gaies, 1983), or "conversational modification" (Doughty \& Pica, 1986), include utterances that initiate negotiation such as clarification requests, confirmation checks, and comprehension checks (Brown, 1991; Doughty \& Pica, 1986; Gass \& Varonis, 1985, 1994; Long, 1980; Pica \& Doughty, 1985; Plough \& Gass, 1993; Porter, 1986; Rulon \& McCreary, 1986; Shortreed, 1993) and utterances that carry out negotiation using modification, repair, or conversational adjustment such as error corrections (Bruton \& Samuda, 1980; Pica \& Doughty, 1985; Porter, 1986; Tong-Fredericks, 1984), prompts or completion of other utterances (Pica \& Doughty, 1985; Plough \& Gass, 1993; Porter, 1986), and self- and other-repetition (Doughty \& Pica, 1986; Pica \& Doughty, 1985; Shortreed, 1993). Apart from analyzing the above two types of utterances of negotiation, researchers have also examined the amount of speech (Long, Admas, Mclean, \& Castanos 1976; Porter, 1986), and various pedagogical moves, turns, types of questions, and syntactic complexity for various purposes of negotiation (Bygate, 1988, Duff, 1986, Gaies, 1983). The three types of analysis correspond to the research concern on three broad categories summarized by Pica and 
Doughty (1985): negotiation of input/output, grammaticality of input/output, and the amount of input/output.

One focus of the research on negotiation has been the differences between teacher-fronted versus peer group talk, the two basic forms of interaction in the classroom where language learning is attempted. Most of the studies that directly compared teacher-led and peer group situations seemed to suggest results in favor of group talk. Researchers claim that although group talk might be limited in producing conversational adjustment or grammatical utterances (Doughty \& Pica, 1986; Pica \& Doughty, 1985), it is better than teacher-fronted talk because it generates greater quantity of language or more negotiated output (Doughty \& Pica, 1986; Pica \& Doughty 1985; Rulon \& McCreary, 1986), produces L2 with a wider range of rhetorical purposes (Long et al., 1976), and demonstrates greater effectiveness in developing language skills (Bejarano, 1987). Peer group, which seems to produce greater quantity and quality of negotiated interaction, as Long and Porter (1985) put it, is "an attractive alternative to the teacher-led, 'lockstep' mode" (p. 207).

However, the studies on NS (native speaker)-NNS (nonnative speaker) and NNS-NNS discourse, which are closely connected to the studies of teacher-led versus group talk, seem to challenge the advantages of peer group talk. Some researchers have hinted that NS teachers need more credit as NSs provide learners with accurate grammatical and sociolinguistic input (Pica, Lincoln-Porter, Paninos, \& Linnell, 1996; Porter, 1986), NS signals of incomprehension help NNSs mod ify their interlanguage toward comprehensible and targetlike production (Pica, 1988), and NNSs comprehend better when they receive modified input from NSs (Gass \& Varonis, 1994). Other researchers have found that although peer groups offer genuine communicative practice (Porter, 1986), learners rarely ask for help, which keeps negotiation to a minimum (McCurdy, 1980). Learners might be capable of using a variety of strategies in error treatment, but their feedback might be in a simplified form (Pica, Holliday, Lewis, \& Morgenthaler, 1989; Pica et al., 1996) or fail in dealing with communication breakdowns (Bruton \& Samuda, 1980). With the insight from the studies on NS-NNS and NNS-NNS discourse, some researchers have realized that interaction between L2 learners "does not provide as much modified input and feedback as interaction with NSs does" (Pica et al., 1996, p. 59).

To account for the inconclusive findings concerning teacher-led versus group interaction or NS-NNS versus NNS-NNS discourse, researchers have examined learners' language backgrounds, types of request signals, and task variables. The findings include the following. First, learners' language backgrounds seem to influence their interaction behaviors, as negotiation is more likely to occur among learners with mixed language background and proficiency (Varonis \& Gass, 1983), or low level of English (Brock, 1985; Rulon \& McCreary, 1986). Second, the types of request signals, whether open-ended 
requests for clarification or models to repeat, influence learners' modification of output (Pica et al., 1989). Teachers or NSs supply learners with target models rather than letting them modify their output (Pica, 1988; Pica et al., 1989). Third, different tasks seem to have different effects on negotiation: role-play and "authentic" interactions draw learners" attention to accuracy whereas problem-solving activities generate language output narrower in form and wider in function (Tong-Fredericks, 1984); drawing tasks produce more negotiation work than picture recognition tasks (Shortreed, 1993); debate activities offer less comprehensible input but longer turns with more complete and complex syntactic constructions than problems-solving tasks (Duff, 1986); information-exchange tasks generate more modification than decision-making tasks (Doughty \& Pica, 1986); and discussion tasks provide potentially equal opportunities for participants to negotiate (Long, 1980).

What emerges from previous studies provides no clear-cut answers of whether teacher-led or group talk is more effective in assisting learners with "structural segmentation of L2 input, access to lexical form and meaning, and production of modified output" (Pica, 1994, p. 493). However, most of the studies have collected data from experimentally well-controlled tasks rather than natural classroom settings where teacher-fronted and group talk exist as a part of everyday classes. In addition, none of the studies has examined learners' perspectives in evaluating and comparing negotiations in teacher-led and group learning situations. These gaps suggest an alternative research approach that the present study has adopted.

\section{Present Research}

\section{Research Questions}

Using a slightly different approach than previous studies, the present study aimed to describe and compare the interaction features of teacher-fronted and group prewriting discussions in the context of an ESL writing program. I followed previous studies on negotiated interactions to analyze and compare participants' amount of production of negotiation, types of utterances that initiate negotiation, and types of utterances that modify output. I also compared students' evaluation of teacher-led and peer group discussions to examine the effects of negotiation in the context of a writing curriculum. The following are the questions I posed to focus the investigation:

1. Does teacher-fronted talk differ from peer group talk in the frequency of participants' utterances of negotiation in classroom discussions?

2. What differences occur in the initiation of negotiation in teacher-led and peer group situations?

3. What differences occur in the way utterances are modified in teacher-led and peer group situations? 
4. How do students evaluate teacher-led and peer group prewriting discussion as learning experiences?

\section{Participants}

Forty-seven students enrolled in three intermediate classes in a summer ESL writing program at a Canadian university participated in the study. ${ }^{1}$ Two teachers taught the three classes; one of them taught both classes $\mathrm{A}$ and $\mathrm{C}$. Both teachers had master's degrees in second language education and had been teaching ESL writing extensively (13 and 12 years respectively). The students were all international students who had just arrived in Canada, with a majority $(79 \%)$ whose L1s were Chinese, Japanese, Korean, or Spanish. Most of the students $(67 \%)$ were in their 20 s, and slightly more than half $(52 \%)$ already had a university degree.

\section{Data Collection Procedures}

The present study, following Rulon and McCreary (1986), focused on tasks of negotiation contextualized as part of the lesson. I chose three writing topics for teacher-led and peer group prewriting discussions from my observation of the same two teachers in a previous study (Shi \& Cumming, 1994). The topics were opinion essays on the common problems of international students studying in Canada, traditional male/female roles, and old people. With the help of the two teachers, I planned the study so that each student had a 20-minute teacher-led discussion and a peer group discussion on two of the three topics. Students were told that they were going to write on the same topics immediately after the discussions. Table 1 shows the procedure of how the variables were distributed.

I audiotaped all three teacher-led and nine peer group discussions and took detailed observation notes of the talking activities. I first transcribed and separated the stream of speech into utterances (Crookes, 1990, see Appendix A for a sample of transcripts). Then, following previous studies, I identified in the discourse two types of interaction features. One type of utterance included those that initiated negotiation such as comprehension checks,

Table 1

Discussion Topics and Classroom Organization

\begin{tabular}{lcc} 
Topics & $\begin{array}{c}\text { Group discussion } \\
(n=44)\end{array}$ & $\begin{array}{c}\text { Teacher-led discus } \\
(n=40)\end{array}$ \\
\hline Old people & Class B $(n=15)$ & Class C $(n=14)$ \\
Traditional roles & Class A $(n=13)$ & Class B $(n=16)$ \\
International students & Class C $(n=16)$ & Class A $(n=10)$
\end{tabular}


clarification requests, and confirmation checks (Brown, 1991; Doughty \& Pica, 1986; Long, 1980; Pica \& Doughty, 1985; Porter, 1986; Rulon \& McCreary, 1986). In addition, I identified in my data feedback requests and misunderstanding remarks that also had similar functions to initiate negotiations. The other type of utterance included those that indicate grammaticality or modification of input/output such as other-completion, completion requests (Pica \& Doughty, 1985; Porter, 1986), and self- and other-corrections (Bruton \& Samuda, 1980; Pica \& Doughty, 1985; Porter, 1986; Tong-Fredericks, 1984, see Appendix B for the nine coding categories and examples). Before coding the entire data, I randomly chose one discussion session and reached an intercoder reliability of $97 \%$ with another researcher.

I tallied the coded utterances in the teacher-led and peer group discussions to examine differences between the verbal behaviors of teachers and students. Considering that individual students' utterances were limited, I focused the analysis on the utterances produced by students as a whole in each class and group. I first calculated the nine interaction features of negotiation in each discussion to compare negotiations in peer group and teacher-led situations. I hypothesized, following some previous studies (Doughty \& Pica, 1986; Pica \& Doughty, 1985; Rulon \& McCreary, 1986), that students would produce a higher frequency of negotiation in groups (statistical tests were not used for the present analysis as some of the features being examined were produced with low frequencies). I then analyzed and compared types of interaction features in teacher utterances in classes with those of students' in groups (the participation of students in classes was too limited for meaningful comparisons). I suspected that teacher-led and peer discussions would differ in how teachers and students used various types of utterance of negotiation.

I conducted an opinion survey after students had completed the two writing activities. Students were asked to write in essay form about their preferences between teacher-led and peer discussions and the reasons for their preferences. As previous studies on negotiated interactions did not look at students' perspectives and preferences, the opinion survey was designed in the present study to explore the issue.

\section{Findings and Discussion}

Research question 1. Does teacher-fronted talk differ from peer group talk in the frequency of participants' utterances of negotiation in classroom discussions?

Comparing the mean frequencies of students' various utterances of negotiation in groups and classes, the present study showed a tendency of group discussions to produce quantitatively more output than class discussions. 
Table 2

Students' Participation in 20-Minute Discussions

\begin{tabular}{lccccc}
\hline & \multicolumn{2}{c}{ Teacher-led discussion } & \multicolumn{2}{c}{ Group discussion } \\
& $M$ & $\%$ & $M$ & $\%$ \\
\hline Student utterances of negotiation & 9.33 & 6.29 & 46.11 & 10.87 \\
Total of student utterances & 148.33 & & 424.22 & \\
\hline
\end{tabular}

This tendency is in accordance with previous findings (Bejarano, 1987; Doughty \& Pica, 1986; Pica \& Doughty, 1985; Long et al., 1976; Rulon \& McCreary, 1986). I found, as Table 2 shows, that group discussions tended to generate proportionately higher frequencies of utterances of negotiation ( $M$ of $10.87 \%$ ) compared with the frequencies of students' utterances in class discussions ( $M$ of $6.29 \%$ ).

An additional observation shown in Table 2 is the relatively small number of utterances of negotiation in the present data compared with previous studies using well-controlled tasks (Doughty \& Pica, 1986; Gass \& Varonis, 1994; Pica \& Doughty, 1985; Rulon \& McCreary, 1986; Shortreed, 1993). The different finding of the present study calls researchers to focus on natural classroom settings because this is where and when language learning might take place for most of the students. Other implications of the small output of negotiation has been mentioned by previous researchers. For example, Early (1987) reported that teachers made many adjustments themselves in their talk to NNS learners to avoid conversational breakdowns. Morrison and Low (1983) also noted that learners monitored their speech without feedback from others in a highly communicative context.

Research Question 2. What differences occur in the initiation of negotiations in teacher-led and peer group situations?

I compared teacher utterances in teacher-led discussions and students' utterances in groups to explore the differences between the ways teachers and students initiate negotiation. As Table 3 shows, students in groups tended to use more comprehension and confirmation checks than teachers; teachers tended to use more feedback and clarification requests than students in groups. ${ }^{2}$ As a result, student peer talk tended to produce restricted negotiation that involved limited modification of language, whereas teacher classroom talk produced extended negotiation with substantial modification. This finding puts a question mark on whether higher frequencies of negotiation in groups mean more effective negotiation and comprehension of meaning. 
Table 3

Teachers' and Students' Utterances that Initiate Negotiation

(M frequencies in 20-minute discussions)

\begin{tabular}{lcc}
\hline & $\begin{array}{c}\text { Teacher talk in classes } \\
M\end{array}$ & $\begin{array}{c}\text { Student talk in groups } \\
M\end{array}$ \\
\hline Comprehension checks & 1.33 & 4.22 \\
Feedback requests & 5.67 & 2 \\
Confirmation checks & 1.67 & 4.11 \\
Clarification requests & 10 & 7.67 \\
\hline
\end{tabular}

Students' Comprehension Checks versus Teachers' Feedback Requests One difference between teacher talk and student peer talk appeared as speakers negotiated to find out what other people thought about what they had said. As Table 3 shows, students in peer groups used more comprehension checks ( $M$ of 4.22 ) than the teachers ( $M$ of 1.33), whereas students used fewer feedback requests ( $M$ of 2 ) than the teachers ( $M$ of 5.67). A comparison of teacher-led and peer negotiation, as shown in Examples 1 and 2 below, suggests that students' negotiation checks produced restricted or even no negotiation, whereas teachers' negotiation requests resulted in deeper and extended negotiation. I use pseudonyms to refer to the students. To help the reader, I indicate students' grammatical errors with $\left[{ }^{*}\right]$ and pronunciation errors with $[x]$; otherwise the transcripts are students' language verbatim without corrections of their interlanguage. ${ }^{3}$

\section{Example 1. Peer discussion on International students}

Pedro: it's the same if you stay in Korea. and suddenly came $\left.{ }^{*}\right]$ millions of Brazilian people...

\begin{tabular}{|c|c|c|}
\hline Comprehension & Pedro: & you understand me? \\
\hline & Kim: & um. \\
\hline Comprehension & Pedro: & what what I mean? \\
\hline & Kim: & um. \\
\hline & Pedro: & $\begin{array}{l}\text { and because Latin people general }[*] \\
\text { talk more than ... }\end{array}$ \\
\hline & Pedro: & talk a lot and talk more level [*]. \\
\hline & Pedro: & you know the Korean. \\
\hline & Pedro: & $\begin{array}{l}\text { I think Korean and Japanese is [*] more } \\
\text { quiet. }\end{array}$ \\
\hline Comprehension & Pedro: & do you understand me? \\
\hline
\end{tabular}


Kim: $\quad$ yeah yeah, I understand.

Pedro: I don't know if you know how Italian people talk.

Pedro: $\quad$ if you go to a city in Italy, people talk (imitates).

Example 2. Teacher-led discussion on Old people

Teacher: anything else?

Kim: the world change.

Kim: sometimes it is difficult to understand.

Teacher: yeah, yeah (writes on the board: adjusting changes in society).

Feedback

Teacher: is this your idea, Kim?

Feedback

Kim: yeah.

Teacher: adjusting to changes in society?

Pedro: $\quad$ sometimes it's very difficult for my grandmother to understand this.

Teacher: $\quad$ can you give me ...

Teacher: give us an example?

Pedro: $\quad$ relations and man and woman.

Pedro: when my grand mother watch [*] TV and see $\left[{ }^{*}\right]$ gays and lesbians ...

Example 1 shows that students' comprehension checks led to little negotiation. Similar observations were also made by Pica et al. (1996) who reported that learners usually responded to comprehension checks with expressions such as "OK, all right, or variants of yes, yeah, or simply no" (p. 64). One reason for this, as Varonis and Gass (1983) have noted, might be that students from similar levels of language proficiency have fewer problems understanding each other.

Example 2 illustrates that teachers tended to use feedback requests to solicit negotiation as well as comprehension. Unlike comprehension checks, which may be responded to simply with Yes or No, feedback requests often leave the addressee no choice but to respond with specific ideas. The teacher requested feedback for what she had categorized as Kim"s idea of "adjusting to changes in society." Although she did not get any response from Kim, Pedro responded with a specific idea that certain things were difficult for old people to understand. The teacher then saw this as an opportunity for the students to elaborate as she asked further for an example. The exchanges illustrate that feedback requests might be more productive than comprehension checks in negotiation. It was interesting to note that the experienced 
teachers in the present study all preferred requesting rather than checking comprehension.

The results of the comparison of teacher and student utterances may imply that many comprehension checks used by the students may function as cues to maintain the verbal discourse rather than meaningful negotiation markers. To verify this point, Table 4 summarizes the frequencies of students' use of comprehension checks.

A number of inferences can be made from the data. First of all, it is clear that comprehension checks were not widely utilized among group members; the comprehension checks of a few individual speakers account for the group total. Second, each individual who used comprehension checks seemed to stick to one or two types of utterances as certain speech habits he or she had developed. Third, as speech habits, most of the comprehension checks might not necessarily result in meaningful negotiation (as I illustrate in the example, Kim responded to Pedro's comprehension checks). It is, therefore, questionable whether comprehension checks are valuable as a basis for much genuine negotiation. Or maybe there should be more refined labels to distinguish those speech patterns from those genuine comprehension checks that aim at real negotiation of meaning.

Table 4

Students' Use of Comprehension Checks in Peer Groups

\begin{tabular}{lcccl}
\hline Students & Groups & Group total & $\begin{array}{c}\text { Individual } \\
\text { frequency }\end{array}$ & Utterances* \\
\hline Samanta & 1 & 7 & 7 & yeah? \\
Simon & 3 & 2 & 2 & right? \\
King & 5 & 6 & 6 & you know? \\
Senia & 6 & 5 & 4 & you know? \\
Ajiez & & & 1 & you know? \\
Ali & 7 & 5 & 5 & you know? \\
Mei & 8 & 5 & 3 & you know? \\
Susanna & & & 2 & Right? \\
Pedro & 9 & 8 & 8 & you know? \\
& & & & you understand ...? \\
\hline
\end{tabular}

"Utterances listed are coded as comprehension checks, not as pause fillers, when speakers were observed to wait for a response from other interlocutors. 


\section{Students' Confirmation Checks versus Teachers' Clarification Requests}

Teachers and students differ not only in how they gain understanding (using comprehension checks versus feedback requests) but also in how they verify understanding (using confirmation checks versus clarification requests) in negotiating meaning. As shown above, students rely more on comprehending checks and teachers rely more on feedback requests to gain understanding. Table 3 also shows that students in groups used more confirmation checks ( $M$ of 4.11 ) than the teachers ( $M$ of 1.67), whereas teachers used more clarification requests ( $M$ of 10$)$ than students did in groups ( $M$ of 7.67). Examples 3 and 4 below illustrate the difference between students' use of confirmation checks and teachers' use of clarification request in finding out what the previous speaker has just said.

Example 3. Peer discussion on Old people

Jilo: but they really want to get a house.

Sam: Oh yeah.

Jilo: $\quad$ they work for for many [!] years.

Jilo: $\quad 40$ years, 50 year, 60 years.

Jilo: $\quad 60$ years and at last -

Confirmation Sonia: 60 ?

Jilo: $\quad$ yeah of course.

Jilo: at last they can get it.

Example 4. Teacher-led discussion on Old people

Teacher: any other problems associated with being very old?

Kim: relationships.

Clarification Teacher: can you explain a little bit about what you mean?

Susanna: somebody, suppose he is old.

Susanna: he lost $\left[{ }^{*}\right]$ many friends.

Susanna: and he is alone in $\left[{ }^{*}\right]$ home.

Teacher: $\mathrm{OK}$.

Example 3 shows that like comprehension checks, confirmation checks used by students tended to involve restricted modification. First, in uttering a confirmation check the students needed only to repeat what they had heard. Then the responses following the confirmations checks, as Pica et al. (1989) have noted, were usually limited to an affirmative or negative response. The present data suggest that confirmation checks may serve lan- 
guage functions other than checking comprehension, such as expressing surprise, disbelief, or disagreement. Example 3 is typical of how students in this study used confirmation checks to express surprise or disagreement. Because of the nature of these utterances, negotiation was restricted in these circumstances. However, confirmation checks and comprehension checks have been identified as evidence of negotiation of meaning, serving as a criterion to argue for negotiated peer talk in L2 classrooms (Bejarano, 1987; Bygate, 1988; Doughty \& Pica, 1986; Long et al., 1976; Pica \& Doughty, 1985; Rulon \& McCreary, 1986). This argument needs to be reassessed.

Example 4 shows teachers relying on clarification requests to focus on students' comprehension. As a result of teachers' explicit requests for clarification, students tended to produce extended modification. It is obvious from the example that Susanna was pushed to elaborate and to clarify her ideas. Unlike confirmation checks that could be responded to with a simple affirmative or negative answer, clarification requests required students to assess their vocabulary and syntax in order to connect meaning to form.

Comparison of students' use of comprehension checks and confirmation checks with teachers' use of feedback requests and clarification requests throws light on the nature of various negotiation markers. The negotiation checks tend to lead to restricted modification compared with the negotiation requests, which tend to lead to extended modification. The fact that students used more checks than requests suggests that peer talk involves simple negotiation, compared with teacher-led talk, which shows evidence of deeper negotiation. These discourse features reflected learners' limited ability in making modifications beyond the surface level. On the one hand, L2 learners were less confident than teachers in making requests and, therefore, preferred to repeat a model for confirmation. They also seemed to need specific requests in order to be pushed to produce elaborated output. On the other hand, the experienced teachers were conscious and skilled in making requests to solicit extended modification (though in short, sequenced turns). Teacher-led classroom discussion, where a teacher prompted students to modify input and output, appeared to have advantages over peer talk, a situation that has been ignored in many previous studies (Bejarano, 1987; Bygate, 1988; Doughty \& Pica, 1986; Long et al., 1976; Pica \& Doughty, 1985; Rulon \& McCreary, 1986).

Research Question 3. What differences occur in the way utterances are modified in teacher-led and peer group situations?

I analyzed various utterances of modification that typically characterized how participants focused on form and meaning relationships as they completed or corrected their own and others' utterances. My observations suggest, as Table 5 illustrates, that students demonstrated more initiation than teachers in other-completion and self-corrections in peer discussions, whereas teachers, using either completion requests or other-corrections, 
Table 5

Teachers' and Students' Utterances of Modification

(M Frequencies in 20-Minute Discussions)

\begin{tabular}{lcc}
\hline & Teachers in classes & Students in groups \\
& $M$ & $M$ \\
\hline Other-completion & 1.67 & 7.44 \\
Completion requests & 1.33 & 0.11 \\
Self-correction & 2.67 & 17.67 \\
Other-correction & 3.33 & 1.67 \\
\hline
\end{tabular}

were efficient in soliciting and guiding language learning toward target-like forms in teacher-led class discussions.

\section{Students' Other-Completion and Teachers' Completion Requests}

Completion moves are made when the interlocutors segment utterances in order to either complete phrases for others or request others to complete phrases for themselves. The segmentation requires considerable knowledge of both syntax and lexis in English. I assume that as students make various completion moves, their knowledge of the target language is tested in communication of meaning. A distinct difference between teacher talk and student peer talk appeared between the two completion moves: other-completion and completion requests. As Table 5 illustrates, teachers used more completion requests ( $M$ of 1.33) than students in groups ( $M$ of 0.11 ), whereas students in groups tended to use more other-completion ( $M$ of 7.44) than teachers did ( $M$ of 1.67). The picture that emerges is of students being passive in responding to teachers' completion requests in class discussions, but being active in interrupting to complete others' utterances in peer groups. Examples 5 and 6 illustrate the differences:

Example 5. Teacher-led discussion on Traditional male/female roles

Teacher: Popal, is there gender disparity in your country?

Popal: in some situations, there is no.

Completion request Teacher: and in some...?

Other-completion Popal: situations, there is.

Teacher: OK.

Example 6. Peer discussion on International students

Mei: they can understand what problems you have. 
Thuy: because you cannot use English more ...

Thuy: $\quad$ good enough to -

Other-completion

Mei:

Thuy:

to let them understand our words.

Susanna:

yes.

Susanna: because it is not our language.

Example 5 illustrates how a teacher invited a student to complete a sentence by stopping with a rising tone in the middle of her utterance. In responding to the teacher's completion request, the student was required to test his knowledge of the syntactic structure of the language. Compared with the completion required by the teachers, Example 6 shows how a student interrupted her partner to offer the next segment of the sentence. The tendency of students initiating the completion of others' utterances in peer groups reveals their active role in testing hypotheses about their syntactic and lexical knowled ge of English.

Teachers' and students' uses of completion requests and other-completion show that prewriting discussions provide students with learning opportunities for segmenting and restructuring language form for the sake of communicating an intended meaning. It is interesting, although not surprising, to find that students in peer groups showed initiative in making othercompletion, but waited politely for teachers' completion requests to make completion moves in class discussions. Once again, peer talk and teacher-led talk have revealed their differences: as teachers in class situations were conscious in inviting students to experience a valid language learning process, students in peer groups actively created and utilized the learning opportunities themselves.

\section{Students' Self-Corrections and Teachers' Other-Corrections}

Like completion moves, error corrections (where learners and teachers stop to correct the form of the language in order to adjust it) are evidence of a language learning process where form and meaning are isolated and adjusted for the benefit of communication. I observed in the present data differences between student peer talk and teacher talk in terms of how errors were identified and treated. As Table 5 shows, students in groups attempted to do self-corrections ( $M$ of 17.67) more frequently than the teachers corrected themselves ( $M$ of 2.67). Conversely, teachers made more other-corrections ( $M$ of 3.33) compared with students in groups ( $M$ of 1.67). Following Van Lier (1988) and Clark (1978), I suggest that a high frequency of self-corrections in peer groups indicates that students might sense distinct responsibilities for learning and producing language accurately among peers. However, I also observed that in spite of the frequent attempts to correct errors, many errors were not diagnosed or treated correctly in groups. 
Students tended to self-correct their errors in peer groups. Errors corrected by the students ranged from vocabulary errors to syntactic errors such as tenses, articles, pronouns, prepositions, and subject and verb agreements. However, as the following example shows, many errors were left unattended.

\section{Example 7. Peer discussion on International students}

Ali: $\quad$ you don't $\left.{ }^{*}\right]$ used to this accent.

Ali: $\quad$ so you can't understand um quickly.

Ali: $\quad$ step by step you can improve your hearing ...

Self-correction

$\begin{array}{ll}\text { Ali: } & \text { your listening. } \\ \text { Mao: } & \text { I think another problem is when we }\left[^{*}\right] \\ & \text { in the ESL and we talk with another } \\ & \text { country }\left[{ }^{*}\right] \text { people. } \\ \text { and they don't know }\left[{ }^{*}\right] \text { their } & \\ \text { vocabulary is right or wrong. } & \text { or pronouncing }\left[{ }^{*}\right] \text { is right or wrong. }\end{array}$

Example 7 shows how a vocabulary error was corrected by Ali himself when he identified the error in using the word hearing and stopped immediately to correct it. Although it is hard to know whether the student would initiate corrections of similar errors in class situations, the high frequency of self-corrections in groups seems sufficient to suggest that these students were conscious of, and sensitive to, language errors. Peer groups provided an environment where students appeared relaxed to produce what they thought and correct what they felt wrong. However, as Example 7 also shows, many errors were not amended in the peer group, a concern that has been raised by previous researchers (Bruton \& Samuda, 1980; Pica \& Doughty, 1985).

Comparing students' self-corrections with teachers' other-corrections shows that students were not able to identify or correct certain errors themselves in groups. For example, errors in pronunciation that could cause communication breakdowns would probably be left untreated in peer groups. In classes, however, the teachers would diagnose such problems and correct them to bridge gaps in communication. The following are examples comparing the results of pronunciation errors in classes and in groups:

Example 8. Teacher-led discussion on Old people

Kim: stubborn [x].

Clarification Teacher: what's that?

Kim: only they ...

Kim: the spelling, S T U B B ORN. 
Other-correction

Clarification

Teacher: oh they become stubborn.

Teacher: stubborn.

Kim: stubborn.

Teacher: say it again?

Kim: stubborn.

Teacher: all right (writes on the board).

Example 9. Peer discussion on International students

Min: maybe we pronounce something in the wrong $\left[{ }^{*}\right]$ and -

Other-correction

Ali: wrong way.

Min: wrong way.

Min: and they don't know your pronounce [*].

Min: they have to know your pronounce [*].

Min: $\quad$ each other $\left[{ }^{*}\right]$ must know your pronounce $\left[{ }^{*}\right]$.

Min: $\quad$ maybe you told somebody $\left[{ }^{*}\right]$ a Lawyer.

Min: he can not know $\left[{ }^{*}\right]$ the lawyer $[x]$.

Min: $\quad$ L AWER.

Min: maybe I spell the word, you can know.

Clarification

Other-correction

Clarification

Ali:

Order?

Min: $\quad$ Lawyer [x].

Ali: $\quad$ Daughter?

Min: yeah.

Ali. Daughter.

Ken: Daughter.

Confirmation

Other-correction

Clarification

Ali: $\quad$ Daughter?

Min: $\quad$ no, Lawyer [X].

Ali: Lower?

Min: Lower.

Ken: oh Lower.

Confirmation

Ali: $\quad$ Lower?

Min: $\quad$ year, Lower.

Min: $\quad$ and they don't know.

The pronunciation errors in the above two examples caused communication breakdowns. Both $\mathrm{Kim}$ and Min resorted to spelling out words to repair the misunderstandings. However, the teacher in Example 8 was able to identify and correct the error, but the students in the group in the Example 9 were 
not. Compared with teacher-led talk where pronunciation errors could be effectively diagnosed, peer talk might lead participants nowhere in repairing comprehension. As illustrated in the example, Min's inaccurate pronunciation of the word lawyer ended up with the word lower. The students, including Min himself, were not sure of the correct pronunciation of the word, as he gave consent to what was wrongly comprehended. If learners from the same native language background, as Porter (1986) claimed, communicate better because of their similar comprehensible interlanguage phonologies, the present data suggest that learners with mixed language backgrounds were unable to cope with communication breakdowns caused by pronunciation errors independently of a teacher's help.

These observations suggest both advantages and disadvantages of peer talk and teacher-led class talk. Peer talk seems to encourage students to identify and correct errors themselves, although not every error might be diagnosed or treated correctly. Teacher-led whole-class talk seems to be more accurate in diagnosing and treating errors. As students tended to initiate self-corrections rather than other-corrections, non-native speakers not yet competent in the target language might lack confidence in correcting their peers' errors.

\section{Research question 4. How do students evaluate teacher-led and peer group prewriting discussions as learning experiences?}

Students' evaluations suggest how they benefited from both teacher-led and peer discussions. A total of 39 students from the three classes wrote evaluation comments at the end of the study comparing the two writing activities. Except for three students who commented on topics, all the other 36 students commented on teacher-led and peer group discussion arrangements when indicating their preferences. Among the 36 students, only one student said he enjoyed neither of the arrangements, five said that they liked both arrangements, 16 preferred peer discussion, and 14 preferred teacher-led discussion.

Peer discussion was the favorite prewriting activity among these students. Commenting on how peer groups helped them generate ideas, students considered peer talk a freer and more thorough negotiation of ideas. The following two comments show how students appreciated the negotiation among peers:

I prefer peer discussion because students can give their opinions freely. We can not only explain our ideas, but also improve our capacity of thought. After discussion, we can put different ideas together. It helps us write easily. Teacher-led class discussion can't permit students to communicate to each other freely. Teacher $\left[{ }^{*}\right]$ sometimes explains her own ideas that restrict students $\left[{ }^{*}\right]$ ideas.

When talking face to face, I say my opinion and defend it. If I don't understand something, I ask students to explain. So when I write the essay 
it is very easy. I don't like the teacher-led discussion, because the teacher and students talk about many things without arguing and explaining completely. I don't believe some of their opinions, therefore I can't write about them.

While evaluating peer talk as their favorite, students also noticed some of its shortcomings. One frequently identified shortcoming was the problem of selection and organization of ideas generated in peer talk. "The biggest problem with group discussion," said one student, "is the organization of ideas." Other concerns raised by the students include the domination of speaking turns by some students and their inability to treat pronunciation errors, which made communication difficult in groups.

Teacher-led discussion was also a highly appreciated prewriting activity. Although some students found the experience more "passive" than peer talk, many other students found teacher-led discussions beneficial in helping them with the organization and accuracy of writing. One positive feeling shared by students who appreciated teacher-led discussion was their comfort with the presence of the teacher as an authority representing an academic standard of writing. The following comments summarize students' appreciation of teacher-led talk:

[Teacher-led discussion] is good for me because I still have no con-

fidence in my English writing. I need to know how my writing is. Is it good or bad? What is good or what is bad? Is the grammar OK? Did I choose the correct word?

We can learn more about how to write correctly and how to organize our thoughts perfectly from the teacher. I think the discussion is the best way to create a good composition.

In sum, these students perceived peer group talk and teacher-led talk to help them in different aspects of writing: the former in generating what to write, the latter in how to write. The two kinds of discussion arrangements were seen to be beneficial for different reasons. Students who wanted to explore ideas prior to writing seemed to enjoy group talk, and those who were concerned about the organization and accuracy of their texts seemed to prefer teacher-led discussions. In a word, these students perceived peer group and teacher-led talk to complement each other to meet various needs of various students.

\section{Summary and Implications}

This study illustrates how peer group teacher-led prewriting discussions can both be useful language learning experiences. Results show that although peer discussions had high frequencies of negotiation, these negotiations were restricted compared with the extended negotiations in teacher-led discus- 
sions. Also, ESL learners in the present study were found to modify their utterances in groups actively. However, when students' errors were diagnosed and corrected by the teachers, as I illustrate by showing how one of the teachers treated pronunciation errors, they resulted in more target-like forms than peer modifications. Finally, students' believed that peer discussion provided more chances for them to explore what to write, whereas teacherled discussion helped them improve the organization and accuracy of their writing.

One implication of the present study-is that teachers need to alternate group and class discussion to meet the needs of various students. For example, as students commented in their evaluations, peer group talk is more efficient in generating and negotiating what to write, whereas teacher-led talk provides more guidance in how to write. Another implication of the study is that teachers need to attend to the advantages and disadvantages of group and class work. Teacher-led discussions, which seem to limit students' participation, should be balanced with learner interactions in groups. Alternatively, group discussions, which seem to be limited in the extent to which utterances are modified and meanings negotiated, need be balanced with class work where teachers can direct students in extended negotiation and provide target-like models of comprehensible input. Future research is needed to examine the effects of discussion and grouping arrangements on students' writing.

Nothing is more fundamental than classroom interaction to the central purpose of teaching and learning. Teacher-led and group talk have been, and will continue to be, in the limelight for research in language education. The findings of the present study support the theoretical claim that L2 learning might be facilitated in negotiated interactions (Pica, 1994; Swain, 1985). My observations also call for a more refined categorization of negotiation features in future research and raise questions about whether more negotiations in peer talk mean better negotiation and learning experiences for ESL students.

\section{Notes}

${ }^{1}$ This article reports the analysis and findings based on data collected for a larger study. See Shi (in press) for analysis of the data on the effect of the prewriting discussions on students' writing scores and use of lexis.

${ }^{2}$ Although misunderstanding remarks also initiate negotiation, I excluded them in my comparisons because both teachers and students used these utterances infrequently ( $M$ of 1 in both teacher-led and peer group discussions).

${ }^{3}$ Some of the other transcribing conventions I used include "?" for rising intonation, "- " for interrupted utterances, "..." for unfinished utterance, " $[1]$ " for stressed word, "ABC" for spelling of the word, ", for pause in the middle of the utterance, and "." for pause at the end of the utterance. 


\section{Acknowledgements}

I thank the teachers and students for their participation; Alister Cumming for his supervision of the study and his comments on a draft of the article; and Merrill Swain, David Olson, Jim Lantolf, Yves Roberge, Sharon Lapkin, Pat Mathews, and the anonymous reviewers for their helpful comments.

\section{References}

Bejarano, Y. (1987). A cooperative small-group methodology in the language classroom. TESOL Quarterly, 21, 483-501.

Brock, C.A. (1985). The effects of referential questions on ESL classroom discourse. Occasional Papers 1. Honolulu, HI: Department of English as a Second Language, University of Hawaii.

Brown, R. (1991). Group work, task difference, and second language acquisition. Applied Linguistics, 12, 1-12.

Bruton, A., \& Samuda, V. (1980). Learner and teacher roles in the treatment of oral error in group work. RELC Journal, 11, 49-63.

Bygate, M. (1988). Units of oral expression and language learning in small group interaction. Applied Linguistics, 9, 59-82.

Clark, E.V. (1978). Awareness of language: Some evidence from what children say and do. In A. Sinclair, R.V. Jarvella, \& W.J.M. Levelt (Eds.), The child's conception of language (pp. 17-43). Berlin: Springer.

Crookes, C. (1990). The utterance, and other basic units for second language discourse analysis. Applied Linguistics, 11, 183-99.

Doughty, C., \& Pica, T. (1986). "Information gap" tasks, do they facilitate second language acquisition? TESOL Quarterly, 20, 305-25.

Duff, P.A. (1986). Another look at interlanguage talk: Taking task to task. In R.R. Day (Ed.), Talking to learn: Conversation in second language acquisition (pp. 147-81). Rowley, MA: Newbury House.

Early, M. (1987). Linguistic input and interaction in the content classroom. TESL Canada Journal, 4(2), 41-58.

Gaies, S.J. (1983). Learner feedback: An exploratory study of its role in the second language classroom. In H.W. Seliger \& M.H. Long (Eds.), Classroom oriented research in second language acquisition (pp. 190-212). Rowley, MA: Newbury House.

Gass, S.M., \& Varonis, E.M. (1985). Task variation and nonnative/nonnative negotiation of meaning. In S.M. Gass \& C.G. Madden (Eds.), Input in second language acquisition (pp. 149-61). Rowley, MA: Newbury House.

Gass, S.M., \& Varonis, E.M. (1994). Input, interaction, and second language production. Studies in Second Language Acquisition, 16, 283-302.

Long, M.H. (1980). Input, interaction and second langurge acquisition. Unpublished doctoral dissertation, University of California, Los Angeles.

Long, M.H., Admas, L., Mclean, M., \& Castanos, F. (1976). Doing things with words-Verbal interaction in lockstep and small group classroom situations. In R.H. Crymes \& J.E. Fanselow (Eds.), On TESOL '76 (pp. 137-53). Washington, DC: TESOL.

Long, M.H., \& Porter, P.A. (1985). Group work, interlanguage talk, and second language acquisition. TESOL Quarterly, 19, 207-28.

McCurdy, P.L. (1980). Talking to foreigners: The role of rapport. Unpublished doctoral dissertation, University of California, Berkeley.

Morrison, D.M., \& Low, G. (1983). Monitoring and second language learners. In J.C. Richards \& R.W. Schmidt (Eds.), Language and communication (pp. 220-50). New York: Longman.

Pica, T. (1988). Interlanguage adjustments as an outcome of NS-NNS negotiated interaction. Language Learning, 38, 45-73. 
Pica, T. (1994). Research on negotiation: What does it reveal about second-language learning conditions, processes, and outcomes? Language Learning, 44, 493-527.

Pica, T., \& Doughty, C. (1985). Input and interaction in the communicative language classroom: A comparison of teacher-fronted and group activities. In S.M. Gass \& C.G. Madden (Eds.), Input in second language acquisition (pp. 115-32). Rowley, MA: Newbury House.

Pica, T., Holliday, L., Lewis, N., \& Morgenthaler, L. (1989). Comprehensible output as an outcome of linguistic demands on the learner. Studies in Second Language Acquisition, 11 , 63-90.

Pica, T., Lincoln-Porter, F, Paninos, D., \& Linnell, J. (1996). Language learners' interaction: How does it address the input, output, and feedback needs of L2 learners? TESOL Quarterly, 30, 59-84.

Plough, I., \& Gass, S.M. (1993). Interlocutor and task familiarity: Effects on interactional structure. In G. Crookes \& S.M. Gass (Eds.), Tasks and language learning: Integrating theory and practice (pp. 35-95). Clevedon, UK: Multilingual Matters.

Porter, P.A. (1986). How learners talk to each other: Input and interaction in task-centered discussions. In R.R. Day (Ed.), Talking to learn: Conversation in second language acquisition (pp. 200-22). Rowley, MA: Newbury House.

Rulon, K.A., \& McCreary, J. (1986). Negotiation of content: teacher-fronted and small group interaction. In R.R. Day (Ed.), Talking to learn: Conversation in second language acquisition (pp. 182-99). Rowley, MA: Newbury House.

Shi, L. (in press). Effects of prewriting discussions on adult ESL students' compositions. Journal of Second Language Writing.

Shi, L., \& Cumming, A. (1995). Teachers' conceptions of second language writing instruction: Five case studies. Joumal of Second Language Writing, 4, 97-111.

Shortreed, I.M. (1993). Variation in foreigner talk input: The effects of task and proficiency. In G. Crookes \& S.M. Gass (Eds.), Tasks and language learning: Integrating theory and practice (pp. 96-122). Clevedon, UK: Multilingual Matters.

Swain, M. (1985). Communicative competence: Some roles of comprehensible input and comprehensible output in its development. In S.M. Gass \& C.G. Madden (Eds.), Input in second language acquisition (pp. 235-53). Rowley, MA: Newbury House.

Tong-Fredericks, C. (1984). Types of oral communication activities and the language they generate: A comparison. System, 12, 133-45.

Van Lier, L. (1988). The classroom and the learner. London: Longman.

Varonis, E.A., \& Gass, S. (1983, March). "Target language" input from non-native speakers. Paper presented to the 17 th annual TESOL convention, Toronto.

\section{Appendix A: Sample of Transcripts From a Teacher-Led Discussion}

Topic: Old people

Clarification

Clarification

Confirmation
Min:
Teacher: yes?
Min:
Min:
Teacher:
Min:
disasful $[*]$.
disasful [*].
disable [*].
again sorry?
disable [*].

Teacher: is this the word you want (write disabled on the board)? 


\begin{tabular}{lll}
\multirow{3}{*}{ Other-correction } & Min: & yes. \\
& Teacher: & disabled. \\
Other-correction & Teacher: & disabled. \\
& say disabled. \\
Clarification & Meacher: & disabled. \\
& Min: & means moving is difficult. \\
& Teacher: OK. \\
& Teacher: so that means um (writes on the board) \\
& Teacher: & or a person't move. \\
& Teacher: & all right (writes on the board). \\
& Teacher: & what else?
\end{tabular}

\section{Appendix B: Coding Categories and Examples}

\section{Categories \\ Comprehension checks \\ Feedback requests \\ Confirmation checks}

Clarification requests

Misunderstanding remarks

Other-completion

Completion requests

Self-correction

Other-correction

\section{Definitions}

The speaker checks if his or her ideas are understood.

The speaker elicits feedback about what he or she has said.

The speaker repeats his or her partner's utterance to check or confirm if he or she has understood or heard correctly what has been said.

The speaker asks the interlocutor to clarify what has been said.

The speaker points out that his or her ideas have been misinterpreted.

The speaker interrupts and completes or adds to what the other person is saying.

The speaker leaves his or her utterance unfinished deliberately as an invitation for the other interlocutor to complete.

The speaker corrects his or her utterances when he or she believes there is a mistake.

The speaker tries to correct the utterance of the other interlocutor.
Examples

Ali: it's very difficult for me. Ali: $\quad$ you know?

Kyung: boycott.

Kyung: right?

Simon: the women can too.

Pilar: the women can too?

Ali: conversation.
Kyun: what?

Kim: but what I mean is not a problem of the government.

Kang: ... they want to dominateJunko: woman [*].

Teacher: but in Brazil-?

Pedro: $30 \%$ a month.

Jilo: $\quad$ so man has has ...

Jilo: had to work very hard.

Mao: $\quad$... in some place $\left[{ }^{*}\right]-$ Teacher: in some places. 